\title{
Desenvolvimento e avaliação de um controlador eletrônico para equipamentos de aplicação de insumos ${ }^{1}$
}

\author{
Claudio K. Umezu² \& Nelson L. Cappelli²
}

\begin{abstract}
RESUMO
Com este trabalho, objetivou-se o desenvolvimento e avaliação de um sistema de controle para compensar a variação na rotação de acionamento dos dosadores de fertilizantes sólidos de um equipamento para formulação, dosagem e aplicação de fertilizantes sólidos no sulco, a taxas variáveis, em função da alteração da temperatura do óleo hidráulico. Desenvolveram-se controladores do tipo PID, para assegurar a manutenção precisa das rotações desejadas nos motores hidráulicos de acionamento dos dosadores de fertilizante. O equipamento foi testado em laboratório, utilizando-se sinais de testes padronizados, onde foi avaliado o seu comportamento em função do aquecimento do óleo hidráulico. Os testes realizados mostraram que o sistema de controle de rotação implementado foi adequado, mantendo inalterado o comportamento do sistema hidráulico, mesmo na ocorrência de variação da temperatura do óleo hidráulico.
\end{abstract}

Palavras-chave: agricultura de precisão, aplicação localizada, controle hidráulico, VRT

\section{Development and evaluation of electronic control system in equipments for application of fertilizer}

\begin{abstract}
The objective of this research was the development and evaluation of a control system used to compensate variation on angular speed of dosers in an equipment for formulation, dosing and application of solid fertilizers in the furrow, at variable rates, by monitoring the hydraulic oil temperature changes. PID controllers were designed to guarantee the desired angular speed of the hydraulic motors dosing shaft. The equipment was tested in laboratory using standard signal tests procedure, being able to analyze the machine behavior as a function of the hydraulic oil temperature variations. The accomplished tests showed that the implemented control system was suitable and exhibited a steady behavior even during hydraulic oil temperature changes.
\end{abstract}

Key words: precision farming, site specific, hydraulic control, VRT 


\section{INTRODUÇÃO}

Segundo Umezu (2003), o termo “Agricultura de Precisão” é utilizado para descrever o uso de diversas tecnologias avançadas, buscando-se a redução dos custos de produção, cuja preocupação diz respeito à preservação do meio ambiente. Conforme diversos autores, a agricultura de precisão pode ser dividida em três grandes etapas: na coleta de dados, com o objetivo de mapear a variabilidade espacial e temporal do campo; na análise de dados e tomada de decisões e na aplicação localizada de insumos agrícolas. As etapas da agricultura de precisão constituem um ciclo que é repetido a cada safra. Para completar o ciclo da agricultura de precisão são necessários equipamentos com capacidade de aplicar, de forma precisa, insumos a taxas variáveis. O desenvolvimento da denominada "Tecnologia de Aplicação Variável” (VRT) requer pesquisas tanto na área de gerenciamento de dados como no projeto de equipamentos dedicados.

Maohua (2001) pondera que em países em desenvolvimento, a agricultura de precisão pode se tornar um problema devido à falta de informação e pessoas qualificadas para a utilização de tais tecnologias. Porém, prossegue o autor, muitos países em desenvolvimento têm se beneficiado da disponibilidade de informações, seguindo modelos ou adaptando novas tecnologias à sua realidade.

Para Saraiva et al. (1998), uma característica importante que muitos dos novos equipamentos devem possuir, é a capacidade de aplicar os insumos a taxas variáveis (como, por exemplo: sementes, defensivos, fertilizantes etc.), o que vem impulsionando muitas empresas a realizarem pesquisa e desenvolver produtos para atender a esta necessidade.

Auernhammer (2001) ressalta que, com a aplicação de fertilizantes, associada à necessidade de um local específico, pode-se obter alta produtividade com economia de aplicação de fertilizantes diminuindo, assim, a poluição ao meio ambiente. Contudo, Cox (2002) justifica que agricultura de precisão não é resultado apenas da utilização de equipamentos de posicionamento, hoje empregados em larga escala, mas sim de um conjunto de equipamentos visando a coleta de dados e a execução de tarefas.

Sudduth (1999) coloca que a tomada de decisões para aplicação localizada de insumos pode ser implementada de maneira on-line ou off-line. Na tomada de decisões de forma on-line ou baseada em sensores em tempo real, o equipamento controlado incorpora sensores, sendo os dados de tais sensores usados imediatamente para o controle automático da aplicação. Nos equipamentos que operam de forma off-line ou baseados em mapas de aplicação, os dados são coletados, armazenados e processados em uma operação distinta e o equipamento utiliza essas informações para efetuar a aplicação. A tecnologia baseada em mapas de aplicação permite maior flexibilidade na manipulação dos dados e no pré-processamento, porém requer que a localização do equipamento no campo seja precisamente definida.

Monico (2000) destaca que a agricultura de precisão utiliza principalmente três tecnologias principais: GPS (Global Positioning System), SIG (Sistema de Informações Geográ- ficas) e VRT. Segundo o autor, o GPS possibilita a localização e a orientação das máquinas em qualquer lugar do campo como, por exemplo, durante uma operação de colheita; o equipamento VRT, integrado ao GPS e SIG, enseja a aplicação de insumos em local específico, com dosagens variáveis. Esta integração fornece informações que permitem aos produtores aplicar insumos como fertilizantes, herbicidas e defensivos, em dosagens e locais apropriados, favorecendo a proteção do meio ambiente.

As máquinas e equipamentos agrícolas comumente possuem dispositivos de força e potência acionados hidraulicamente. Nos sistemas hidráulicos, a temperatura do óleo pode atingir níveis indesejáveis, já que sua viscosidade pode tornar-se muito baixa ou, até mesmo, o óleo pode vir a se deteriorar, causando falha na lubrificação e conseqüentes danos mecânicos. Henke (1983) apresenta as causas da geração de calor nos circuitos hidráulicos e métodos para sua redução.

Tradicionalmente, considerações térmicas sobre os sistemas hidráulicos têm sido uma fonte de problemas de engenharia. Na maioria das vezes, o foco no projeto de sistemas hidráulicos é direcionado aos aspectos de vazão e pressão e nas suas demandas, deixando que as considerações térmicas sejam tratadas de forma prioritária; contudo, a necessidade de sistemas hidráulicos otimizados quanto ao seu desempenho, exigem soluções para o problema. Nesses sistemas não basta que a temperatura do óleo hidráulico permaneça dentro dos níveis aceitáveis; é necessário, ainda, que eles sejam compensados para anular a influência da variação de temperatura do óleo nos seus parâmetros de desempenho. A compensação da alteração no desempenho do sistema pode ser realizada por meio de sistemas automáticos de controle.

Sistemas de controle têm sido cada vez mais utilizados em máquinas e equipamentos agrícolas. É comum se encontrar tratores e colhedoras agrícolas equipados com diversos sistemas automáticos para controle de tarefas que, tradicionalmente, eram realizadas pelo próprio operador da máquina.

Segundo Scarlett (2001), a implantação de sistemas de controle para a automação pode gerar um incremento de 15 a 20\% na eficiência de operação do trator agrícola. Além da maior eficiência na operação mecânica, a implantação de sistemas de controle ajuda a reduzir o esforço mental do operador, diminuindo sua fadiga e aumentando seu rendimento e qualidade de trabalho.

Ogata (2003) afirma que mais da metade dos controladores industriais em uso atualmente, emprega esquemas de controladores PID (Proporcional + Integral + Derivativo). Ainda segundo o autor, a utilidade dos controladores PID está na sua aplicabilidade à maioria dos sistemas de controle.

Os controladores PID são bastante utilizados nas indústrias para controle de: nível de líquidos, temperatura, velocidade de rotação de motores, posicionamento mecânico, de vazão e pressão em máquinas elétricas em geral, entre outros.

Foi propósito se desenvolver e avaliar um sistema de controle para compensar a alteração na rotação de acionamento dos dosadores de fertilizantes sólidos de um equipamento para aplicação, proposto por Oliva et al. (2001) em função da variação da temperatura do óleo hidráulico. 


\section{MATERIAL E MÉTODOS}

\section{Descrição do equipamento VRT}

Como ponto de partida deste trabalho, utilizou-se o protótipo de um equipamento para aplicação de fertilizantes sólidos a taxas variáveis, cujo projeto mecânico foi desenvolvido por Oliva et al. (2001). O modelo original utilizado como base foi uma semeadora-adubadora, com capacidade para oito linhas de aplicação. O equipamento original possui um sistema de distribuição de adubo que utiliza dosadores tipo helicoidal flutuante e unidades de distribuição de adubo, de discos duplos desencontrados. Rodas compactadoras flutuantes fazem a cobertura das sementes, enquanto controladores de profundidade, flutuantes e independentes, controlam a profundidade de aplicação. O equipamento, em sua configuração original possui, ainda, um sistema pneumático de distribuição de sementes, acionado pela tomada de potência do trator e um sistema de acionamento dos eixos dos distribuidores realizado por rodas de terra e câmbio mecânico, para regulagem das respectivas rotações.

A Figura 1A mostra uma visão do equipamento utilizado como base deste trabalho, enquanto a Figura $1 \mathrm{~B}$ indica o diagrama esquemático do sistema de acionamento dos dosadores. As adaptações consistiram em mudanças em diversas partes do equipamento. O sistema mecânico de acionamento e transmissão foi substituído por um sistema hidráulico, com controle de vazão, por meio de válvulas proporcionais controladas eletricamente.

O protótipo do equipamento se compõe de uma bomba hidráulica de engrenagens acoplada, através de uma caixa de transmissão, ligada à TDP de um trator agrícola. Três motores hidráulicos, marca Eaton, modelo CHAR-LYNN, série 2000, do tipo orbital, acionam diretamente eixos que comandam cada conjunto de quatro dosadores. As rotações de cada motor são controladas individualmente, através de três válvulas proporcionais de vazão, compensadas a pressão, marca HidraForce, modelo PV7230A10TN24DG; também, fazem parte do circuito uma válvula limitadora de pressão, reser- vatórios de óleo hidráulico e conexões hidráulicas e elementos mecânicos.

Adotou-se uma configuração com a qual se procura aproveitar melhor a potência disponível no sistema de acionamento, fazendo com que cada um dos motores acione um conjunto de quatro dosadores. O protótipo do equipamento de aplicação de fertilizantes sólidos, a taxas variáveis, possui quatro linhas de aplicação e opera a partir de informações proveninentes de mapas de aplicação de fertilizantes e de um receptor de GPS.

\section{Sistema de instrumentação}

Para medição e registro do comportamento do equipamento, utilizou-se um sistema de instrumentação de aquisição de dados, marca HBM, modelo MGCplus, constituído de uma unidade de processamento, interface com o usuário, placas de amplificação e condicionamento de sinais. O sistema de aquisição e processamento de sinais foi configurado para medir, processar e armazenar os sinais de comando das válvulas de controle de fluxo, a rotação dos eixos de acionamento dos dosadores e, ainda, a temperatura ambiente e a temperatura do óleo hidráulico.

\section{Aplicativo para o controle do equipamento}

Optou-se pela implementação do controlador, utilizandose o ambiente de desenvolvimento LabVIEW, versão 5.1, desenvolvido por National Instruments, para a implementação do sistema de controle do equipamento. Desenvolveram-se rotinas para leitura da posição e velocidade de deslocamento do equipamento, a partir de informações do GPS, controle da rotação dos motores hidráulicos e controle geral do equipamento.

\section{RESULTADOS E DISCUSSÃO \\ Integração dos sistemas}

Para o correto funcionamento do equipamento foi necessário se projetar e implementar o sistema de acionamento
A.

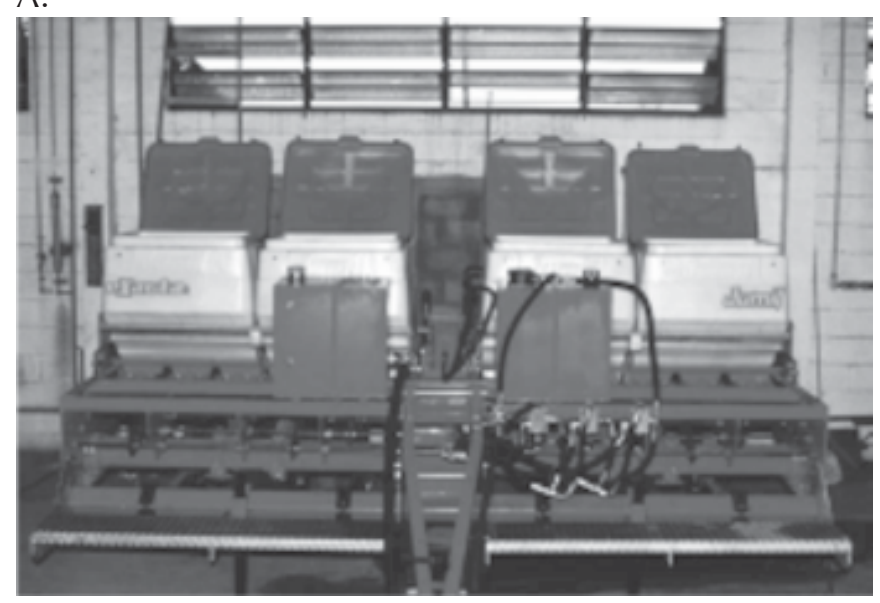

B.

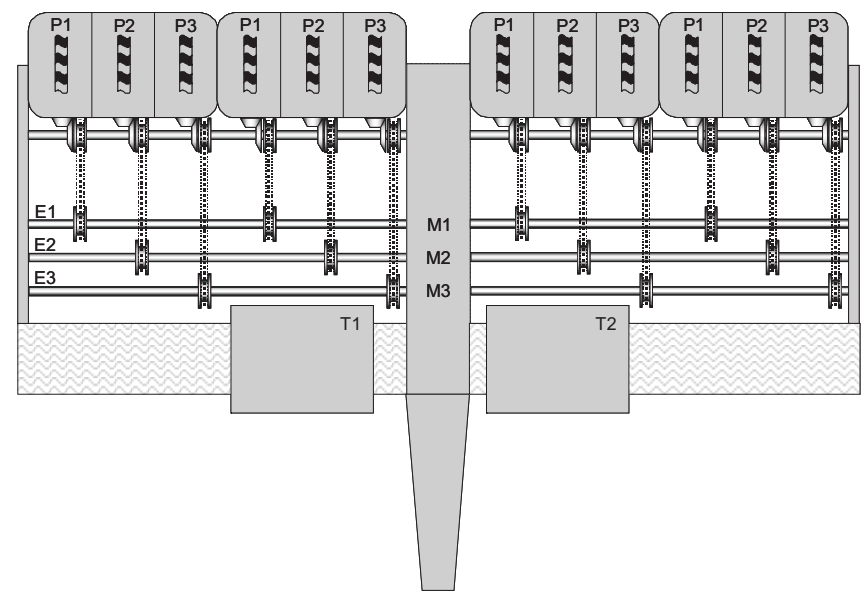

Figura 1. (A) Equipamento para formulação, dosagem e aplicação de fertilizantes sólidos a taxas variáveis. (B) Diagrama esquemático do sistema de acionamento dos dosadores (P1, P2 e P3: reservatórios de fertilizantes, T1 e T2: reservatórios de óleo hidráulico, M1, M2 e M3: motores hidráulicos, E1, E2 e E3: eixos de acionamento dos dosadores). 


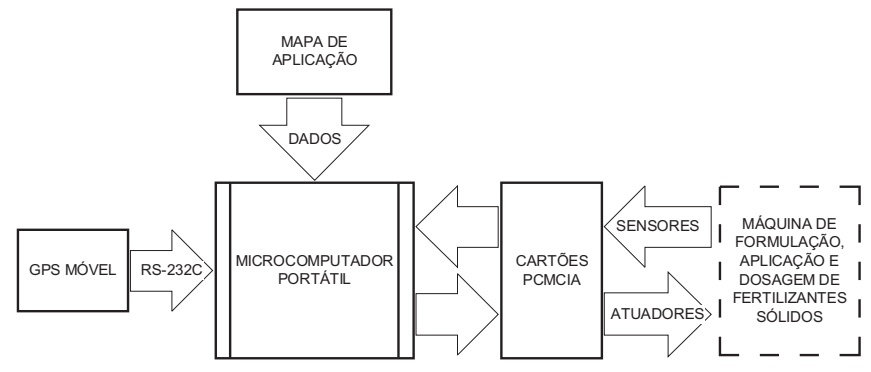

Figura 2. Integração dos componentes eletrônicos

e controle eletrônico de rotação dos motores hidráulicos e, também, a interface com o sistema de GPS, fazendo com que o equipamento fosse capaz de alterar a formulação e a dosagem de fertilizantes, de acordo com sua posição georreferenciada.

Projetou-se o sistema de controle do equipamento de aplicação utilizando-se, como elemento principal de controle, um microcomputador. Por razões de portabilidade e robustez, adotou-se uma plataforma computacional, baseada em uma plataforma padrão PC (Figura 2).

O microcomputador tem a função de gerenciar o funcionamento do equipamento durante a operação normal e realização dos teste e, nele, foram instalados dois cartões de entrada e saída de sinais (National Instruments, modelo DAQCard 1200); o programa principal de controle e monitoramento, desenvolvido em ambiente LabVIEW, e sub-rotinas para leitura do sinal de GPS além de controle de rotação dos motores hidráulicos.

\section{Descrição do funcionamento do sistema de controle}

Inicialmente, o microcomputador recebe e processa as informações do GPS, fornecidas no formato NMEA-0183, através de uma interface serial, padrão RS-232C. A partir dos dados de posicionamento, o aplicativo lê as informações dos mapas de aplicação, referentes a cada um dos fertilizantes utilizados. As informações contidas no mapa podem ser interpretadas como informações de rotação de cada um dos dosadores.

Para a especificação da rotação dos dosadores, também é necessária a determinação da velocidade de deslocamento do equipamento. Uma velocidade de deslocamento maior se traduz em uma rotação também maior dos dosadores, enquanto uma velocidade de deslocamento menor se traduz em uma rotação menor dos mesmos, para um mesmo ponto no mapa de aplicação.

\section{Controladores de rotação}

Para o correto funcionamento do equipamento é conveniente o controle preciso da rotação dos motores de acionamento dos dosadores. Para tanto, desenvolveram-se controladores de rotação implementados no ambiente de desenvolvimento LabVIEW. Projetaram-se e se implementaram controladores do tipo Proporcional + Integral + Derivativo (PID), com realimentação de saída. Neste tipo de sistema de controle a rotação real é comparada com a rotação desejada, gerando-se um sinal de erro que é então aplicado ao controlador.
Os controladores PID para a rotação dos motores têm, como entrada, um sinal de referência de rotação, obtida a partir do mapa de aplicação de insumos. Os controladores PID recebem, como entrada, a rotação desejada e a rotação real, medida pelos sensores de rotação. A partir da diferença entre as rotações desejadas e as reais, os controladores PID calculam o valor dos sinais de atuação que serão então aplicados aos amplificadores PWM.

Para a ajustagem dos parâmetros dos controladores, aplicou-se o segundo método de Ziegler-Nichols, válido para sistemas que se desestabilizam com um ganho de realimentação. Para se obter um desempenho melhor dos controladores PID ajustou-se, manualmente, cada um dos ganhos dos parâmetros de forma individual, procurando-se os valores combinados que fornecessem os melhores resultados ao controle da rotação do motor.

\section{Controle geral do equipamento}

Desenvolveu-se um aplicativo com a função de ler o mapa de aplicação localizada de insumos e a posição geo-referenciada, a partir do receptor de GPS, calcular a velocidade e a direção de deslocamento do equipamento, gerar os sinais elétricos de comando das válvulas proporcionais, armazenar e indicar, na tela do computador, os dados de desempenho e condições operacionais do equipamento e seus subsistemas.

Uma das sub-rotinas do programa principal, lê e interpreta o mapa de aplicação localizada de insumos armazenado na forma de arquivo e o compara com a posição geo-referenciada e a velocidade de deslocamento do equipamento. O aplicativo gera, então, os sinais de comando, através das saídas D/A dos cartões PCMCIA, para os amplificadores PWM, que controlam as válvulas proporcionais. As rotações instantâneas de cada motor são lidas pelos sensores de rotação instalados nos eixos de acionamento dos dosadores. Caso seja necessário, o sistema de controle realimentado irá atuar, corrigindo a rotação dos motores.

A intervenção do operador é requerida quando há ausência de matéria-prima em um dos depósitos, quando ocorrerem seguidos erros de posicionamento, quando o mapa de aplicação não corresponder à posição geo-referenciada do equipamento ou, ainda, se os sensores de rotação detectarem problemas no acionamento dos dosadores.

\section{Testes dinâmicos do comportamento do sistema em função do aquecimento do óleo}

Uma característica não desejada, porém bastante usual de sistemas hidráulicos, é a alteração de seu comportamento, em função da temperatura do óleo hidráulico. Oliva et al. (2001) realizaram testes para determinação do comportamento da rotação dos motores, em função do aquecimento do óleo hidráulico, concluindo que existe ligeira tendência de aumento da rotação dos motores com o aumento da temperatura do óleo hidráulico.

Neste trabalho foram realizados testes dinâmicos para avaliação do comportamento do sistema, em função do aquecimento do óleo hidráulico e, nos testes, realizaramse sucessivas alterações nas rotações dos motores, avaliando-se o seu comportamento, em função do aquecimento do 
A.

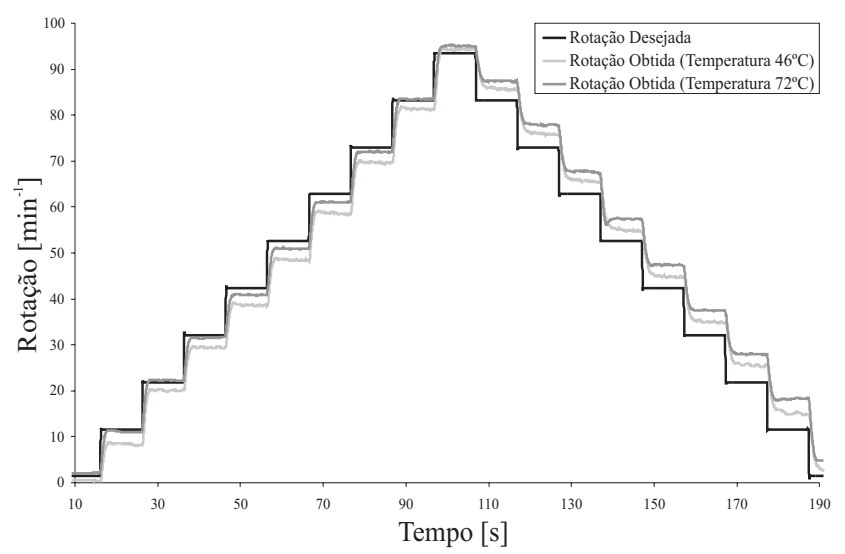

B.

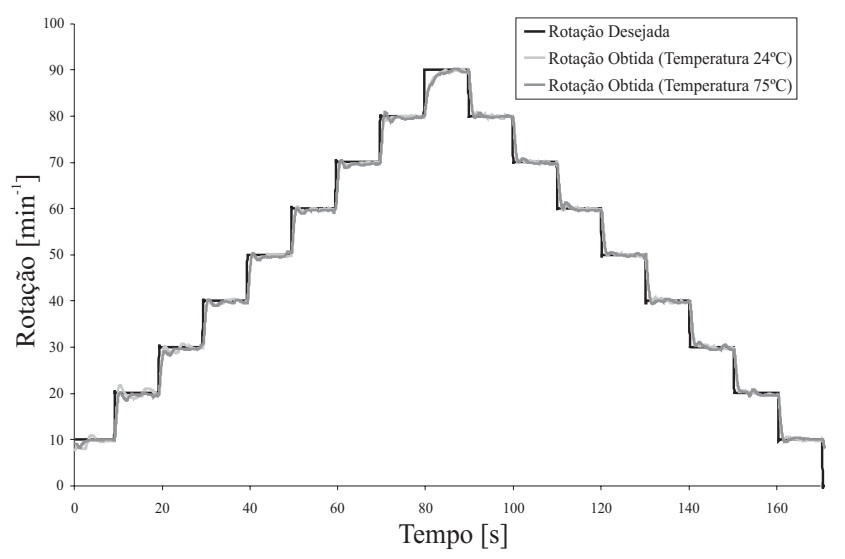

Figura 3. (A) Comportamento da rotação do motor com o aquecimento do óleo sem a presença de controladores de rotação. (B) Comportamento da rotação do motor com o aquecimento do óleo com a presença de controladores de rotação do tipo PID.

óleo hidráulico. Foram realizados experimentos com e sem a presença dos controladores de rotação, utilizando-se um sinal de teste do tipo degraus múltiplos. Na Figura 3A são apresentados os resultados obtidos sem a presença de controladores de rotação. Realizaram-se testes, inicialmente com o óleo hidráulico, a uma temperatura de $46{ }^{\circ} \mathrm{C}$ e, posteriormente, com o óleo aquecido a uma temperatura de $72{ }^{\circ} \mathrm{C}$.

Analisando-se o comportamento da rotação do motor em função do aumento da temperatura (Figura 3A), nota-se tendência de elevação da rotação e, para valores crescentes de solicitação, a rotação obtida se manteve em níveis inferiores aos desejados, enquanto para valores decrescentes de solicitação a rotação obtida se manteve em níveis superiores aos esperados; este comportamento pode prejudicar a precisão do sistema, pois um mesmo sinal de comando pode resultar em diferentes rotações do eixo e, portanto, diferentes taxas de aplicação de fertilizantes, dependendo da temperatura do óleo hidráulico.

Com a introdução dos controladores de rotação do tipo PID, repetiram-se os testes dinâmicos para avaliação do comportamento do sistema, em função do aquecimento do óleo hidráulico. Novamente foram realizados dois experimentos, o primeiro com o óleo hidráulico a temperatura de $24{ }^{\circ} \mathrm{C}$ e o segundo com o óleo aquecido a uma temperatura de $75^{\circ} \mathrm{C}$ (Figura 3B).

Com a utilização dos controladores PID, as rotações se mantiveram praticamente inalteradas, mesmo com a alteração da temperatura do óleo hidráulico, dentro dos limites estudados. Destaca-se que nos testes com os controladores PID, o óleo hidráulico foi submetido a uma amplitude térmica superior à dos testes sem controladores. Os resultados obtidos são muito importantes, pois eliminam grandes preocupações na manutenção de uma temperatura constante do óleo hidráulico para que se possa garantir um perfeito funcionamento do sistema. Destaca-se, também, o fato de que o óleo hidráulico deve ser mantido dentro dos seus limites operacionais, evitando problemas de superaquecimento e perda das suas características funcionais.

\section{CONCLUSÕES}

1. Os controladores PID, implementados em LabVIEW, mostraram-se bastante eficazes e versáteis.

2. Com a introdução dos controladores PID eliminaramse os problemas de histerese e aqueles decorrentes do aquecimento do óleo hidráulico.

3. Os testes realizados mostraram que o sistema de controle implementado foi adequado para utilização no protótipo do equipamento para formulação, dosagem e aplicação de fertilizantes sólidos, a taxas variáveis.

\section{AGRADECIMENTOS}

À Empresa Jumil - Justino de Morais, Irmãos S/A, pelo empréstimo e pelas modificações no chassi do equipamento.

À Fundação de Amparo à Pesquisa do Estado de São Paulo - FAPESP, pelo apoio financeiro a este trabalho.

Ao Laboratório de Instrumentação e Controle da FEAGRI - UNICAMP, pela cessão de sua infra-estrutura.

\section{LITERATURA CITADA}

Auernhammer, H. Precision farming - the environmental challenge. Computers and Electronics in Agriculture, Amsterdam, v.30, p.31-43, 2001.

Cox, S. Information technology: the global key to precision agriculture and sustainability. Computers and Electronics in Agriculture. v.36, n.2-3, p.93-111, 2002.

Henke, R. W. Fluid power systems \& circuits. Wisconsin: hydraulics \& pneumatics Magazine, 1983. 355p.

Maohua, W. Possible adoption of precision agriculture for developing countries at the threshold of the new millennium. Computers and Electronics in Agriculture, Amsterdam, v.30, n.1-3, p.45-50, 2001.

R. Bras. Eng. Agríc. Ambiental, v.10, n.1, p.225-230, 2006. 
Monico, J. F. G. Posicionamento pelo NAVSTAR-GPS: Descrição, fundamentos e aplicações. São Paulo: Editora Unesp, 2000. 287p.

Ogata, K. Engenharia de controle moderno. 4.ed. São Paulo: Prentice Hall do Brasil, 2003. 788p.

Oliva, R. A. G.; Cappelli, N. L.; Umezu, C. K. Máquina para aplicação de fertilizantes sólidos a taxas variáveis - Adaptação de um modelo comercial convencional. In: Congresso Brasileiro de Engenharia Agrícola, 30, 2001, Foz do Iguaçu. Anais... Foz do Iguaçu: SBEA, 2001. 1CD.

Saraiva, A. M.; Cugnasca; C. E.; Paz, S. M. O problema da padronização e integração de sistemas na agricultura de precisão. In: GIS Brasil, Curitiba. 1998. Mostra Especial.
Scarlett, A. J. Integrated control of agricultural tractors and implements: a review of potential opportunities relating to cultivation and crop establishment machinery. Computers and Electronics in Agriculture, Amsterdam, v.30, n.1-3, p.167-191, 2001.

Sudduth, K. A. Engineering technologies for precision farming. In: International Seminar on Agricultural Mechanization Technology for Precision Farming, 1999, Suwon. Anais... Suwon: Rural Development Admin.1999, P.5-27.

Umezu, C. K. Sistema de controle de um equipamento de formulação, dosagem e aplicação de fertilizantes sólidos a taxas variáveis. Campinas: UNICAMP, 2003. 171p. Tese Doutorado. 